\title{
Using a Personalized Learning Style and Google Classroom Technology to Bridge the Knowledge Gap on Computer Science
}

\author{
https://doi.org/10.3991/ijet.v15i02.11602 \\ Zhanat Kopeyev ( $\left.{ }^{凶}\right)$, Akan Mubarakov \\ L.N. Gumilyov Eurasian National University, Nur-Sultan, Kazakhstan \\ zhanat_kb@mail.ru \\ Jaroslav Kultan \\ University of Economics in Bratislava, Bratislava, Slovakia \\ Gaukhar Aimicheva \\ L.N. Gumilyov Eurasian National University, Nur-Sultan, Kazakhstan \\ Yessenkeldy Tuyakov \\ Abay Kazakh National Pedagogical University, Almaty, Kazakhstan
}

\begin{abstract}
The article is devoted to the challenge of bridging the knowledge gap on computer science in context of the Kazakhstani education. The authors discuss the main reasons of gap in knowledge on computer science at first-year students and suggest suitable teaching to solve the indicated challenge. The considered teaching is based on the principle of continuity to teaching which provides correlation between various levels of education and improving the effectiveness of teaching.

The different levels of the students' learning outcomes on computer science are considered as one of the most important cause of the investigated challenge. For this reason, the authors investigate the educational process design and the differentiated learning methodology using the Google Classroom technology aimed to the bridging knowledge gap in computer science.
\end{abstract}

Keywords - Computational thinking, knowledge gap in computer science, continuity, differentiated learning, learning outcomes, Google Classroom technology

\section{Introduction}

Nowadays one of the important skills of any employees and more over computer science students is a computational thinking skill, which needs to be developed at both educational levels: at high school and at university. According to the published researches the computational thinking is a special thinking which can develop and improve during learning the computer science, information and communication 
technologies, programming, mobile application development [1] - [8]. But most of the authors consider the computational thinking development only in context of the one educational level, at high school or at university. It is evidence about the lack of continuity of learning content.

Recently due to an increased recognition of the importance of computational skills in the global economy, there has been an increase in the undergraduate Computer Science (CS) program enrollments by $300 \%$ [9]. But the high school graduates have different levels of learning outcomes on computer science. And this leads to another issue of incorrect perception of computer science, computer science major and computing-related careers due to insufficient career counseling and applicationscentric high school computing curricula. Survey has shown that only $13.04 \%$ of participants taking a computer programming course in high school. This fact directly reflects on the students' achievement on computer science in university. The authors see the solution of the problem in curriculum overhaul in order to form more in-depth knowledge of computer science in the high school course and to successfully adapt to the university learning content in accordance with the growing requirements of the global economy for IT-majors [9].

Thus, there is a research gap in the issue of continuity learning between the high school and university. Many authors discussed the similar issue in their research field and suggested appropriate decisions. So, authors [6], [7] consider to be correct learning the programming from elementary school to universities in order to develop the computational thinking and modern soft-skills. They suggest to choose an educational strategy, which provided progressive enhancement of computational thinking skills from the high school to the university level, combining different environments and programming languages.

To bridging gap in physics knowledge in higher school and further effective study engineering students at the university the authors [10] propose to develop information literacy through the collaborative work of teachers, lecturers and librarians and to introduce changes in curricula at different educational levels. They emphasize the role of educators' collaboration at different educational levels and continuity of learning content.

Some researchers suggest [11] an adaptive e-learning system to bridging the gaps in the students' knowledge and to improve the learning outcomes for students with different domain knowledge. Such adaptive e-learning system offers students individual learning content due to the basic knowledge of the subject area and student's learning style. It has been experimentally proven that learning content, adapted to the needs of students, improved learning outcomes compared to using common learning content. Similar approach based on the collaboration of school teachers and university faculty and the adaptation of learning content to achieve better learning outcomes was suggested in work [12].

So, many authors for bridging the knowledge gap propose the continuity of learning content, collaboration of educators and using the differentiated approach for better adapt students to learning content in depends of the background knowledge and to achieve best learning outcomes at university. 
The following research question will be addressed in this study: «How to bridging knowledge gap in the computer science to achieve sufficient level of computational skills through the differentiated learning?».

\section{Current State of Educational System of Kazakhstan}

One of the strategic directions of Kazakhstan's development is improvement of education and science providing intensification the economic and technological progress, political and cultural development. Over the years of reforms many innovative projects have been implemented in Kazakhstan. At the present state the main challenge of education development is its modernization aimed to achieve high level of preparation the younger generation to real life [14]. In the new political and economic environment, the organization of the educational process in secondary schools and universities was designed to ensure a planned character of the educational process, a modern educational and scientific level of training of graduates, the implementation of new science and technology achievements in the educational process and its optimization based on the effective use of information technologies, a rational combination of traditional and innovative teaching methods [15].

With the development of the concept of continuing education, great emphasis is placed on continuity. In the context of continuing education concept great importance should be given to the continuity of learning content not only within one educational level but also between different educational levels.

Continuity between high school and university education is a sequence of pedagogical activities providing development of learning and teaching processes due the dialectical relation with the previous learning and with accordance to the goals and objectives of the developing process.

The main issue related to continuity between high school and university is different level of background knowledge of first-year students. This issue arising from the insufficiently designed high school and university curricula. The difficulties of the first-year students is deal with the low level of background knowledge along with the high requirements at university, transition from strong control at school to self-control at university.

According to the continuity principles, teaching should be developed as a logically designed system correlated with the goals, content, methods, tools at all educational levels, which ensures student's personality progressive development.

The problem of continuity in teaching Computer Science is covered quite widely in pedagogical literature. In the works the emphasis is put on revealing conditions, factors, and ways of studying and ensuring continuity in teaching Computer Science in relation to high school or university education.

The problem of continuity of high school and university education is far from new to pedagogy and it would seem well researched in many aspects. However, in practice, many high school graduates, who face university stage, have difficulty in their learning activities - they find it difficult to adapt to new forms of organization of learning and teaching, requirements for learning outcomes. In other words, there is 
unconformity in the content and in the methods as well as in learning tools applied at high school and university. Nature and techniques of learning activities of high school and university students are significantly differ [16].

Study of teaching and learning process related to high school and university students is conducted separately. After all, transition from high school education to university education is the most crucial stage.

The urgency of the problem, its significance determined the topic of this work.

\section{Materials and Methods}

Review and analysis of scientific sources on the topic under study led to the fact that many scientists covered various problems of teaching Computer Science in their research: methodology and substantiation of scientific conceptual framework of Computer Science and informatization of education; content and methodological basis of teaching Computer Science at high school and university; development and use of electronic educational resources, social aspects of Computer Science, use of automated learning systems in teaching and learning at university.

After analyzing different authors' works it is possible to draw such a conclusion that for implementing continuity principle when teaching Computer Science at high school and university it is necessary to take into account students' individual characteristics, their interests, background knowledge level and the rate of learning more fully [9] - [13]. It is more convenient to organize progression of students to the learning goals following the lines of different complexity degrees of educational content using levelled differentiation of learning in providing constant assessment and correction of the learning process [11], [13]. Differentiated learning is one way to optimize learning process and to bridging gap in knowledge. Differentiated learning is proposed differentiated at several levels hands-on tasks for students and differentiated criteria for evaluating their learning outcomes.

Differentiated learning can be built by both scientific-theoretical profiles and scientific-technical ones. Differentiated learning can also be implemented in the form of optional classes using the time allocated for this purpose by the curriculum.

Differentiation of learning includes:

- Ensuring students' needs and capabilities when studying particular subject;

- Implementation of the conformity principle regarding the level of knowledge and skills to the requirements stipulated by university;

- Clear gradation of complexity levels of learning material;

- Determining the level of knowledge and readiness to learn a new topic.

The use of these forms and methods one of which is differentiation according to levels (based on students' individual characteristics) creates favorable conditions for learner development in context of the learner-centered educational process.

To implement differentiated learning in practice methodological support is required. The basis for its development should be a levelled approach to structure and content of methodological and didactic manuals, which would simultaneously ensure 
achievement of compulsory basic training and would enable students to master a higher level of acquisition of learning content.

Looking at content of a Computer Science course that has to be obligatory studied at high school today's high school graduate must know the basics of programming and must be trained in working with operating system, MS Word, MS Excel, MS Access, etc.

Testing background knowledge of first-year students conducted during two years of research included simple questions on the topics that have been studied at high school.

After analysis the following data about the average level of learning outcomes on Computer Science school course was obtained (see see Figure 1).

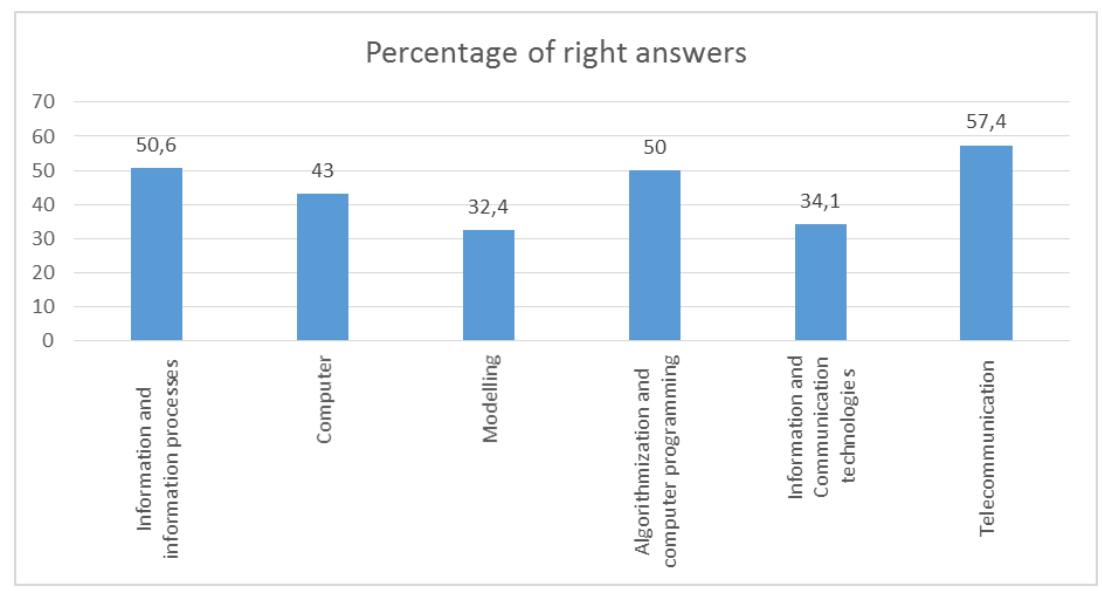

Fig. 1. The average level of learning outcomes on Computer Science school course

The study revealed that the worst learning outcomes were shown in the «Modelling» section (32.4\%), «Information and Communication Technologies» $(34.1 \%)$, «Computer» (43\%). Good acquisition of learning material on Sections «Information and information processes», «Algorithmization and computer programming», «Telecommunications».

For example, a school curriculum related to studying the topic of MS Excel does not go further charting, at best. Basically, yesterday's schoolchildren can perform adding and subtracting in MS Excel. Most of them have no idea about using even the simplest functions; $90 \%$ of first-year students did not even hear about data filtering, summing, data consolidation, search for optimal solutions [17].

By analyzing the results of the study, we can say about the lack of continuity between high school and university when studying disciplines related to information technology. Therefore, as before, there is still need to study (or revise) all sections necessary for formation of future specialist's computer literacy at university. This requires additional hours or it is necessary to eliminate the gaps in high school education through in-depth study of information technology. 
Thus, there is no doubt that the main way to implement continuity at high school and university education is differentiation of learning.

Differentiation of learning - is pedagogical correction of general readiness of firstyear students to continue their studies at university - purposeful planning of students' activities taking into account their individual capabilities and abilities - the use of various methods of stimulating educational and cognitive activity in high school and university.

Differentiation of learning is currently one of the key areas of high school modernization.

Computer Science as an academic subject provides especially great opportunities for implementation of differentiated learning caused by:

- Firstly, potential of information technology introduced to learning process by Computer Science;

- Secondly, wide interdisciplinary links of this academic discipline;

- Thirdly, a significant applied component of education content - is a means of information technology and methods of their use in various fields of human activity which provides a natural sphere of education content differentiation.

The need for differentiated learning in relation to learners follows from the fact that learners differ in their inclinations, types of memory, level of preparation, perception of the world, personality traits. The teacher's task is to enable students to show their individuality, imagination, creativity, save them from the feeling of fear and instill self-confidence. Differentiated learning allows each learner to work at their optimal pace, gives an opportunity to cope with the task, promotes an increase of interest in learning activities, forms positive motives for learning.

In addition, when teaching Computer Science there is a need for differentiation in computer skills: students have different levels of knowledge in Computer Science, different computer access possibilities for doing homework and meeting their interests related to use of modern computer technologies (working with text and graphic editors, use of Internet resources, etc.).

\section{$4 \quad$ Results and Discussion}

Educators face the question of how to plan educational process. In general, educators work according to a general curriculum for all learners, certainly this also reduces learning motivation for some students. Some students have a lack of motivation due to the fact that they already know the material being studied, these are students with a good level of knowledge, while others have less motivation due to a lack of understanding of the material being studied, due to the lack of background knowledge as well as an insufficient level of learning outcomes in the field of Computer Science.

Therefore, now the work is formed by means of differentiated learning, tasks are prepared for three groups: weak, medium and strong. The overwhelming majority of students usually have medium level of knowledge and this is a group that has a 
sufficient level of knowledge, but not in-depth, tasks are prepared for them in accordance with the standard with a detailed explanation of the execution algorithm, which they usually perform on their own, without any special teacher's explanations. Weak group is also quite large, tasks with a reduced level of difficulty are prepared for them and all tasks are performed with a detailed explanation. A strong group, which is the smallest one, is often no more than 2-3 people with in-depth knowledge in Computer Science and ICT. They are offered tasks of increased complexity and are explained algorithm for the task execution. They usually also perform them on their own, only occasionally asking for clarification. When working with a weak group the teacher has to fill in the gaps in their knowledge, so there is less time left to work with medium and strong groups. In general, it turns out that teacher is forced to work only with a weak group in the classroom, only paying attention to the medium and strong groups fragmentarily. As expected by the end of the course the weak group joins middle group, while middle and strong groups of students also receive new knowledge and accordingly it represents development in the field of Computer Science. But, if there were only medium and strong groups initially then the percentage of this development would be significantly higher [18].

One of the main goals of «Computer Science» subject is formation of student's hands-on computational skills and abilities, i.e. in addition to theoretical knowledge in the field of IT technologies a student has to be able to use information technologies competently and to work with application software without any difficulty. Through the new opportunities of the different social media like social networking sites, collaborative projects, blogs, wikis, communities, forums, content platforms, etc., young people not only communicate freely, but also can create and share their feelings, opinions and emotions. One of the areas which experienced the inevitable changes under the growing use of social media, is higher education. On the one hand, students continue to use social media in universities as well as any other sphere of their lives. On the other hand, educators embrace the opportunities of social media to engage students in the process of creating and sharing knowledge and in more efficient ways of communication [19]. The use of information and communication technologies (ICT) in education has led to the transformation of 21 st century classrooms into innovative learning environments characterized as connected, flexible and collaborative [20]. Student can learn to work in software environment only when having hands-on sessions. One of these options for training differentiated learning oriented to levels is application «Google Classroom» that can be used.

The Google classroom is known as a popular tool to ensure the process of teaching and learning. Experimental studies confirm the increased interest of students who prefer to study in Google classroom, where the teachers play passive roles [21].

Classroom helps teachers to save time, organize learning process and communicate with students effectively. This service is available to all users of Google Apps for Education - is a free service package for organizing work efficiently, which also include Gmail, Disk, and Documents (see Figure 2).

The Classroom application allows you to take photos and attach them directly to tasks, share images, PDF files, and work without Internet connection. 

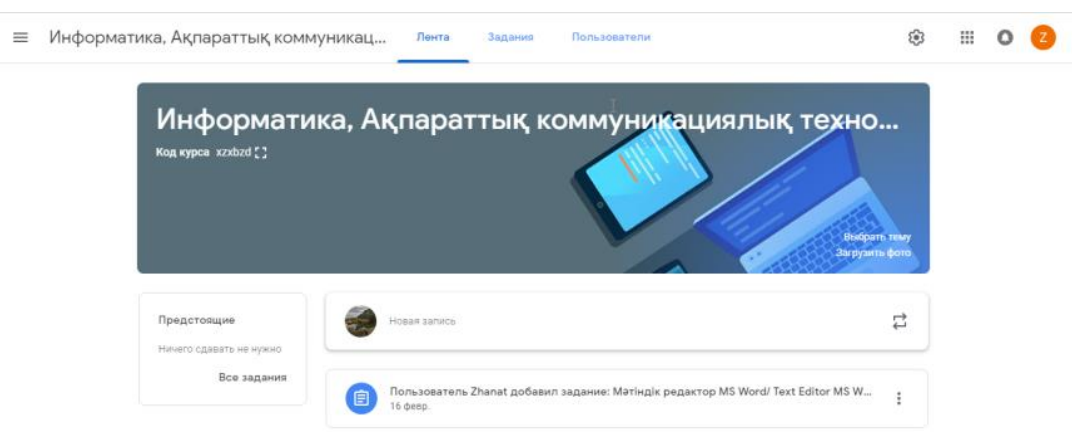

Fig. 2. Using Google Classroom

Features of Google Classroom are as follows:

- Learners can be added in a convenient way. The teacher can send an invitation to students to a created course using domain user groups that have previously been created by the administrator

- Co-teaching - is an opportunity to invite up to 20 other teachers to the course

- Differentiated learning - is the ability to create individual tasks for each student

- Setting up tasks - is the ability to add deadlines, change rating scale and track tasks that were checked

- Preliminary preparation - is the ability to create drafts of notes and tasks or set up the date and time of their automatic publication in the course feed

- Setting up course topic - is the ability to change color scheme and themes in a default mode

- Tracking assignments for students - Google Classroom creates a Google Calendar for each course and updates tasks and deadlines. Students can view tasks in the feed, on the page of works and in the calendar of the course

- Transfer of marks - is the ability to export final marks to Google Spreadsheets or CSV file, which can be downloaded to other applications

- Also Google Classroom is available on the Internet and through Google Class mobile application for Android and iOS

«Google Classroom»- is a technique having the concept of a lesson-lecture and homework when a teacher looks through a lecture on a specific topic at home before a lesson and classroom time is devoted to practical work, projects and discussion. The main concepts of this methodology are: active study of the material, strong motivational base, transformed learning process and digital recording of the material.

However, before introducing this technology into educational process, one should consider the differences between traditional and non-traditional teaching methods (see Table 1).

Traditional teaching of Computer Science general education course is that teachers work with all students following the same program and using the same tasks for them focusing primarily on «medium» student or on the students having minimum level of 
knowledge in the study group and thus their individual characteristics are not fully taken into account [22].

Table 1. Comparison of teaching methods

\begin{tabular}{|c|c|c|}
\hline Learning process & Traditional & $\begin{array}{c}\text { Lesson with the use of «Classroom» } \\
\text { service }\end{array}$ \\
\hline $\begin{array}{l}\text { Lesson teaching } \\
\text { technique }\end{array}$ & $\begin{array}{l}\text { The teacher explains new material, students } \\
\text { consolidate the skills acquired. }\end{array}$ & $\begin{array}{l}\text { Teacher directs learners' activities to solve } \\
\text { difficult questions and develop skills. }\end{array}$ \\
\hline $\begin{array}{l}\text { Learning } \\
\text { technique }\end{array}$ & $\begin{array}{l}\text { Teacher explains new material, students } \\
\text { consolidate their skills. Students perform } \\
\text { tasks on their own at home }\end{array}$ & $\begin{array}{l}\text { Students watch videos independently, } \\
\text { prepare questions. The teacher directs } \\
\text { students' activity to solve difficult } \\
\text { questions and develop skills. }\end{array}$ \\
\hline $\begin{array}{l}\text { Knowledge } \\
\text { transfer }\end{array}$ & $\begin{array}{l}\text { Teaching material is handed over from } \\
\text { teacher to trainer in a passive form. }\end{array}$ & $\begin{array}{l}\text { Knowledge is acquired independently with } \\
\text { elements of interactive communication. }\end{array}$ \\
\hline Technique & Interactive technology & $\begin{array}{l}\text { Communication, cooperation, } \\
\text { collaboration }\end{array}$ \\
\hline Methods & Differentiated & Differentiated, personalized \\
\hline ICT & Multimedia and web technology & $\begin{array}{l}\text { Office, Google, Web-2, Moodle services, } \\
\text { etc. }\end{array}$ \\
\hline Trainer & $\begin{array}{l}\text { Trainer studies according to the } \\
\text { implementation scheme «listen - remember } \\
\text { - reproduce», plays the role of a mentor and } \\
\text { transfers, controls knowledge and maintains } \\
\text { discipline and order. }\end{array}$ & $\begin{array}{l}\text { Trainer is responsible for his/her training. } \\
\text { He/she interacts with all participants of } \\
\text { educational process. }\end{array}$ \\
\hline Teacher & $\begin{array}{l}\text { Teacher transfers and controls knowledge, } \\
\text { maintains discipline and order. }\end{array}$ & $\begin{array}{l}\text { Teacher carries out structure planning of } \\
\text { learning activity, plays the role of a } \\
\text { mentor. }\end{array}$ \\
\hline
\end{tabular}

Judging by the table it can be concluded that «Google Clasroom» is the basis for implementation of differentiated, individualized learning; active learning conditions are created; latest technology and a variety of gadgets are used; educational process is organized according to each student's needs; conditions for teamwork are created; students' leadership qualities are developed in the framework of academic subjects; conditions for determining quality of knowledge using computer technology are created.

\section{Conclusion}

In conclusion, we would like to emphasize the continuity of high school and university education concerns not only the content of education, but also the forms, methods and means of education including socio-psychological conditions of moral development as well as psychological and pedagogical conditions for development computational skills and creative personality.

Use of differentiated learning in teaching Computer Science course at school and university based on determining students' learning outcomes allows to improve quality of education and thereby to increase the level of students' knowledge and computational skills significantly necessary for their life in the information-oriented society. 
In our opinion, differentiated learning technique can be introduced for levelling off students' knowledge as a tool for successful learning. Implementation of differentiation in learning process is possible through Google Classroom technology as it enables to make learning process more effective as well as more interesting and teachers will receive an effective tool for building an individual learning path.

This research has proved the practicability of differentiated learning to bridging knowledge gap in computer science and achieve sufficient level of computational skills. The results of research is particularly valuable for researches in the field of study methodological base of teaching Computer science and developing computational skills.

\section{References}

[1] Jeannette M. Wing. Computational thinking. Commun. ACM, 49(3):33-35, March 2006.

[2] Valerie Barr and Chris Stephenson. Bringing computational thinking to k-12: What is involved and what is the role of the computer science education community? ACM Inroads, 2(1):48-54, February 2011. https://doi.org/10.1145/1929887.1929905

[3] Ann Gouws, Karen Bradshaw, and Peter Wentworth. Computational thinking in educational activities: An evaluation of the educational game light-bot. In ACM Conference on Innovation and Technology in Computer Science Education, ITiCSE '13, pages 10-15, New York, NY, USA, 2013. ACM. https://doi.org/10.1145/2462476.2466518

[4] Ljubomir Perković, Amber Settle, Sungsoon Hwang, and Joshua Jones. A framework for computational thinking, In Conference on Innovation and Technology in Computer Science Education, ITiCSE '10, pages 123-127, New York, NY, USA, 2010. ACM. https://doi.org/10.1145/1822090.1822126

[5] Valerie J. Shute, Chen Sun, and Jodi Asbell-Clarke. Demystifying computational thinking. Educational Research Review, 22:142 - 158, 2017. https://doi.org/10.1016/j.edurev.2017. $\underline{09.003}$

[6] Buitrago Flórez, F., Casallas, R., Hernández, M., Reyes, A., Restrepo, S., \& Danies, G. (2017). Changing a generation's way of thinking: Teaching computational thinking through programming. Review of Educational Research, 87(4), 834-860. https://doi.org/10. $\underline{3102 / 0034654317710096}$

[7] Dodero, J.M., Mota, J.M., \& Ruiz-Rube, I. (2017). Bringing computational thinking to teachers' training: a workshop review. In Proceedings of the 5th International Conference on Technological Ecosystems for Enhancing Multiculturality (p. 4). ACM. https://doi.org/ $10.1145 / 3144826.3145352$

[8] Morelli, R., de Lanerolle, T., Lake, P., Limardo, N., Tamotsu, E., \& Uche, C. (2011). Can android app inventor bring computational thinking to k-12. In Proc. 42nd ACM technical symposium on Computer science education (SIGCSE'11). https://doi.org/10.1145/2157136. 2157437

[9] Stone, J.A. (2019). Student perceptions of computing and computing majors. Journal of Computing Sciences in Colleges, 34(3), 22-30.

[10] Zorana Ercegovac. (2003). Bridging the Knowledge Gap Between Secondary and Higher Education. College and Research Libraries, 64, 75-85. https://www. researchgate. net/publication/279437426. https://doi.org/10.5860/crl.64.1.75

[11] Siadaty, M., Taghiyareh, F. (2007): PALS2: Pedagogically Adaptive Learning System based on Learning Styles, icalt, (pp. 616-618), 7th IEEE International Conference on 
Advanced Learning Technologies (ICALT). DOI: 10. 1109/ICALT. 2007. 198. Retrieved from https://www. researchgate. net/publication/221424232. https://doi.org/10.1109/icalt. 2007.198

[12] Offir, B., Barth, I., Lev, Y. \& Shteinbok, A. (2003). Teacher-student interactions and learning outcomes in a distance learning environment. Internet and Higher Education, 6(1), 65-75. Elsevier Ltd. Retrieved May 20, 2019 from https://www. learntechlib. org/p/96514/. https://doi.org/10.1016/s1096-7516(02)00162-8

[13] Bruner, J. S. The Process of Education. (Cambridge, MA: Harvard University Press, 1960).

[14] A.E. Abylkassymova, E.A.Tuyakov. (2018). On modernization of the system of continuous pedagogical education in the republic of Kazakhstan in modern conditions. PONTE International Journal of Sciences and Research. J. Ponte - Jan 2018 - Volume 74 Issue 1. http://www.pontejournal.net/mainpanel/abstract.php?TOKEN=gRkgF5411G\&P ID=PJ-MSPZ4

[15] S. Shuinshina, Y. Tuyakov, Y. Alpeissov, L. Zhanseitova, A. Ardabayeva. (2019). Modernization of the system of continuous natural science education in the republic of Kazakhstan. AD ALTA: Journal of Interdisciplinary Research. VOLume. 8, ISSUE 1, Special issue IV. http://www.magnanimitas.cz/ADALTA/080104/papers/A_25.pdf

[16] Filatova LO. 2006. The development of the continuity of school and university education under profile education at the senior level of the school // Newsletter of Omsk State Pedagogical University. Humanitarian research. Retrieved from http://www.omsk.edu/ article/vestnik-omgpu-96.pdf. (in Russ.).

[17] Moiseyev VO. and Stepanova YUV. (2013). Effective succession of high school and university concerning IT-teaching as an issue of contemporary education // Bulletin of Kazan Technological University. Retrieved from https://kpfu.ru/staff_files/F1669296641/ EFFEKTIVNAYa_PREEMSTVENNOST_ShKOLA_VUZ_pdf (in Russ.)

[18] Kholmogorova EI. (2014). Secondary School - Higher Education Institution continuity in the Field of Information Science. Humanities vector. Pedagogy. Retrieved from http://oaji. net/articles/2014/938-1402745204.pdf

[19] Aleksandrova Y., Parusheva S. (2019) Social Media Usage Patterns in Higher Education Institutions - An Empirical Study. iJET - Vol. 14, No. 5, https://doi.org/ 10.3991/ijet.v14i05.9720

[20] Spela Bagon and Mateja Gacnik. (2018). Information Communication Technology Use among Students in Inclusive Classrooms, iJET - Vol. 13, No. 6, p.56. https://doi.org/10. 3991/ijet.v13i06.8051

[21] Rana A. Saeed Al-Maroof and Mostafa Al-Emran (2018). Students Acceptance of Google Classroom: An Exploratory Study using PLS-SEM Approach, iJET - Vol. 13, No. 6, p.113. https://doi.org/10.3991/ijet.v13i06.8275

[22] Dekina AP. 2004. Methodical approaches to ensuring continuity in informational training of students of pedagogical universities: On the example of the general educational course of computer science. Moscow. Retrieved from https://elibrary.ru/item.asp?id=16042395 (in Russ.)

\section{$7 \quad$ Authors}

Zhanat Kopeyev \& Gaukhar Aimicheva, are doctoral students at Department of Computer Sciences, Faculty of Information technologies, L.N. Gumilyov Eurasian 
National University, Satpayev str 2, 140000, Nur-Sultan, Kazakhstan, zhanat_kb@mail.ru, aimicheva@mail.ru

Akan Mubarakov, Dr. Sci. (Pedagogical), Professor, Department of Computer Sciences, Faculty of Information technologies, L.N. Gumilyov Eurasian National University, 140000, Nur-Sultan, Kazakhstan, akan-mubarak@mail.ru

Jaroslav Kultan, PhD Doctor, Department of Applied Informatics, Faculty of Economic Informatics, University of Economics in Bratislava, 85235, Bratislava, Slovakia,jkultan@gmail.com

Yessenkeldy Tuyakov, Associate Professor, Candidate of Pedagogical Sciences, Abay Kazakh National Pedagogical University, 050000, Almaty, Kazakhstan, t.esen.a@mail.ru

Article submitted 2019-08-31. Resubmitted 2019-10-09. Final acceptance 2019-10-09. Final version published as submitted by the authors. 